\title{
Determinants of Antibiotics Prescribing among Doctors in a Nigerian Urban Tertiary Hospital
}

Olayinka O. Ogunleye ${ }^{1,2}$, Joseph O. Fadare ${ }^{3}$, Adesola F. Yinka-

Ogunleye ${ }^{4}$, Bene D Anand Paramadhas ${ }^{5}$ Brian Godman ${ }^{6,7}$

\section{Authors Affiliations:}

1. Department of Pharmacology, Therapeutics and Toxicology, Lagos State University College of Medicine, Ikeja, Lagos, Nigeria. Email: yinkabode@yahoo.com

2. Department of Medicine, Lagos State University Teaching Hospital, Ikeja, Lagos, Nigeria

3. Department of Pharmacology and Therapeutics, College of Medicine, Ekiti State University, Ado-Ekiti, Nigeria. Email: jofadare@gmail.com; joseph.fadare@eksu.edu.ng

4. Nigerian Center for Disease Control, Abuja, Nigeria. Email: dessyleye@yahoo.com

5. Department of Pharmacy, Nyangabgwe Hospital, Francistown, Botswana. Email: anandbene@yahoo.com

6. Division of Clinical Pharmacology, Department of Laboratory Medicine, Karolinska Institutet, Karolinska University Hospital, Huddinge, Stockholm, Sweden. Email:

Brian.Godman@ki.se

7. Strathclyde Institute of Pharmacy and Biomedical Sciences, University of Strathclyde, Glasgow, U.K. Email: Brian.Godman@strath.ac.uk

\section{Corresponding Author}

\section{Dr. Olayinka O. Ogunleye}

Department of Pharmacology, Therapeutics and Toxicology

Lagos State University College of Medicine

1-5, Oba Akinjobi Street, Ikeja GRA

Lagos, Nigeria.

Tel: +234 8053357057

E mail: yinkabode@yahoo.com and olayinka.ogunleye@lasucom.edu.ng

(Accepted for publication Hospital Practice - please keep Confidential) 


\section{Abstract:}

Background and Objective

The problem of antimicrobial resistance (AMR) has assumed pandemic dimensions especially among low and middle income countries such as Nigeria. Irrational use of currently available antimicrobial agents is a major contributory factor. There remains a paucity of documented information on the determinants of antibiotics prescribing among physicians in Nigeria to guide future strategies to reduce AMR. This study therefore aimed to investigate the patterns and determinants of antibiotics prescription among doctors in a tertiary hospital in Nigeria as the first step to improve future antibiotic use in hospitals.

Methodology

A cross sectional survey of the determinants of antibiotic prescribing among doctors in the Lagos State University Teaching Hospital, Ikeja, was performed using a structured questionnaire. Information was obtained about the doctors and the factors determining their prescription of antibiotics. The results were summarized using descriptive statistics with Statistical Package for Social Science (SPSS).

Results

98 respondents were studied with a mean age of 36.24(9.01) years, mean duration of practice of $10.68(9.25)$ years, and mainly males (64.3\%). 97\% prescribe antibiotics frequently, mostly based on clinical judgment and experience with rare laboratory supports. Factors of cost, drug availability and information from pharmaceutical representatives influenced antibiotic prescribing. There were indications of nonexistence or non-functional institutional policies and guidelines regarding antimicrobial therapies.

Conclusion

There is an urgent need to institute evidence based institutional policies and guidelines for improving antimicrobial use among hospitals in Nigeria. This is already being followed up

Key words: antibiotics; prescribing; hospital; doctors; Nigeria.

\section{Introduction}

The problem of antimicrobial resistance (AMR) has assumed pandemic dimensions especially among Low and Middle Income Countries (LMICs) such as Nigeria [1,2]. 
AMR now poses a serious threat to global health, increasing morbidity, mortality and costs if not addressed [3-7]. Recent reports revealed its occurrence in all regions of the world and the potential to affect anyone, of any age, and in any country, leading to calls to develop appropriate plans across countries [8,9]. Records of resistance to carbapenem antibiotics that are used as last resort for life threatening infections now exist in practically all regions of the world. [1] Similarly, there is increasing resistance to widely used third generation cephalosporins and fluoroquinolones occasioned by increasing use of antibiotics $[1,10]$. This has led to calls for international collaboration to reduce future rates of AMR including calls by World Health Assembly to member states to publish their national action plans towards combating drug resistant infections especially antibiotic resistant bacteria with a deadline which expired in May 2017 without satisfactory responses. [8, 11, 12, 13].

The prevalence of AMR documented across Africa, including Nigeria, remains high $[2,14-15]$. . As a resultin Nigeria, there is a substantial decline in the susceptibility of antibiotics commonly used for empirical treatments.. Examples include $88 \%$ of Staphylococcus aureus infections now resistant to methicillin, over $98 \%$ resistance to $\beta$ lactam antibiotics in post-operative wound infections, susceptibility rates below $60 \%$ to empiric antibiotics in urinary tract isolates and below 50\% for antibiotics used for empiric treatment of patients with community acquired pneumonia [16-18].

Major contributory factors to AMR are the irrational use of currently available antibiotics and uncurtailed access to antibiotics [19]. These factors have resulted in excessive use of antibiotics with resultant increase in AMR and concomitant strains on the health care systems $[2,6,20-22]$. Other predisposing factors to AMR include healthcare environment factors such as regulatory policies and infection control practices, lack of guidelines as well as patient pressure [23-25].

Globally, there is evidence that prescribing physicians still have limited knowledge and incorrect practices regarding antibiotic prescribing [26]. Factors influencing physicians prescribing of antibiotics include the severity and duration of infections, patient's expectations, fear of complications, diagnostic uncertainties and the influence of pharmaceutical companies [26-28]. Inappropriate antibiotic prescribing can also emanate from contextual factors such as a lack of existing guidelines, cultural factors such as the influence of peers, and behavioural factors such as the perception of decision autonomy by prescribers. [29]. Prescribing etiquette is also seen as as a major determinant 
of antibiotic prescribing practices among physicians. [30]. Furthermore, Calbo et al in their review also outlined physicians' level of training, motivation, work load, practice settings, access to diagnostic techniques, and services of infectious diseases consultants, as factors influencing antibiotic prescribing [31].

The benefits of appropriate antibiotic prescribing include direct positive impact on clinical outcomes, efficient use of healthcare resources, avoidance or reduction of adverse drug effects as well as the prevention of emergence of drug resistant bacteria $[6,23,31]$. To undertake this and reduce AMR, physicians need adequate knowledge of the patterns of antimicrobial sensitivity in their facilities as well as comply with approved evidence based guidelines [32,33]. This can be part of antimicrobial stewardship programmes (ASPs), which have proven to be effective with improving subsequent antibiotic use [34, 35]. ASPs should be designed with knowledge of the determinants of antimicrobial prescribing among physicians, with acknowledgement that much work still needs to be undertaken around such initiatives in LMICs [29, 36].

There remains paucity of documented information on the determinants of antibiotics prescribing among physicians in Nigeria, which is important given that Nigeria is the most populous African nation coupled with the high burden of infectious diseases in sub-Sahara Africa [32, 37, 38]. This study therefore aimed to investigate the patterns and determinants of antibiotic prescribing among doctors in a tertiary hospital in Nigeria as the first step to improve future antibiotic use in hospitals. This survey also serves as a pilot for a national survey on the subject across Nigeria

\section{Methodology}

The study design was a quantitative cross sectional survey conducted among the prescribing doctors who attended a hospital grand round on the subject of the rational use of antibiotics at the Lagos State University Teaching Hospital, in Ikeja, Lagos, Nigeria. This included whether prescriptions are for originators or generics (INN International non-proprietary name) since the cost of medicines is mostly out-of-pocket. The hospital is a major referral center in Lagos metropolis with a bed capacity of 774 beds and is one of three tertiary centers serving an estimated catchments population of over 19 million people in Lagos State, Nigeria. Consequently, if there are concerns with antibiotic prescribing in this centre, such concerns may well be magnified in nonteaching hospitals including secondary hospitals. A self-administered structured 
questionnaire was used to collect data comprising of the socio demographic characteristics of the doctors and the potential factors determining their prescription of antibiotics prior to the delivery of a presentation by one of the co-authors (OO). There were169 prescribing doctors employed by the hospital at the time of the survey. All 98 doctors who were in attendance at the grand round when the presentation was delivered participated. Respondents maintained anonymity as they did not require documenting any identifiable personal information.

\subsection{Ethical Approval}

The study received ethical approval from the Hospital Ethics Committee and verbal consent was received from the responding participants.

\subsection{Statistical Analysis}

Statistical tests were performed using Statistical Package for Social Science version 15.0. Data explored and the results were summarized with descriptive statistics.

Continuous variables were expressed as mean with standard deviation and categorical variables as proportions.

\section{Results}

Among the 98 (58\%) respondents, 63 were males (64.3\%) and 35 females (35.7\%), with a good representation of most clinical specialties and professional ranking/status of doctors in the hospital at that time (Figures 1 and 2).

\section{Figure 1 - Clinical speciality of respondents}

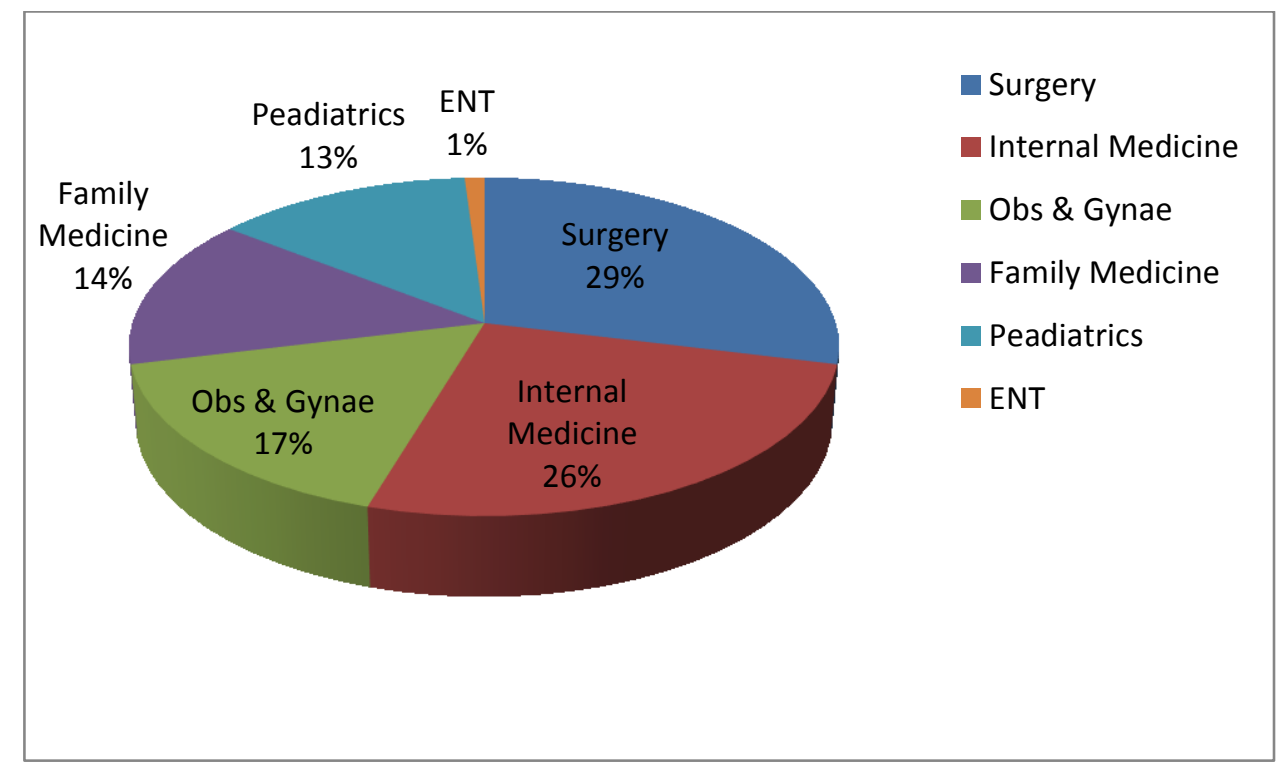




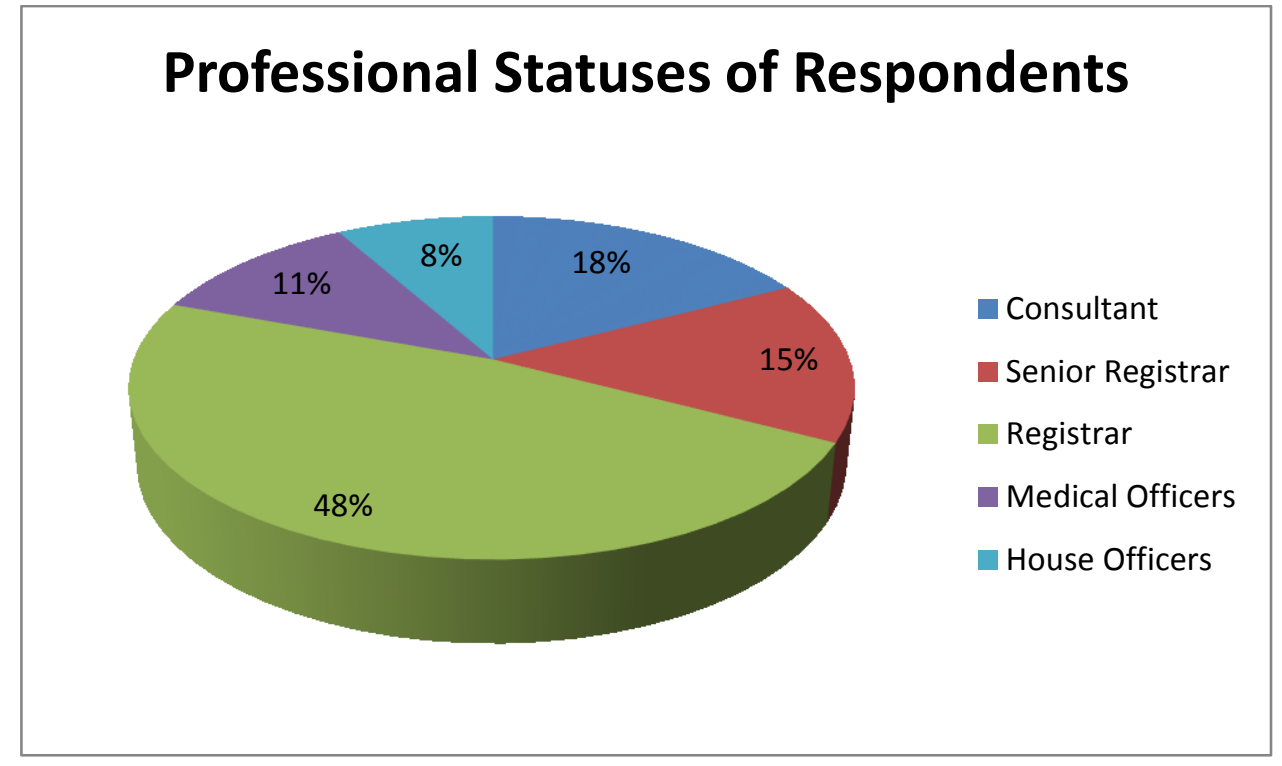

Their mean age was 36.24(9.01) years and mean duration of professional practice was $10.68(9.25)$ years. The majority of the doctors (97\%) prescribed antibiotics in their daily practices. Over $97 \%$ indicated that their choices were influenced by drug promotional and marketing activities of pharmaceutical industry. Other major factors influencing prescribing included the use of clinical judgment (93.9\%), professional experience $(87.8 \%)$, as well as consideration of the costs to patients $(80.6 \%)$, as most patients pay out of pocket, and drug availability (80.6\%). Positively, over $70 \%$ of respondents indicated that they consider local epidemiology of bacterial infections, literature evidence and a senior colleagues' decision in their prescribing decision. However, only $45.9 \%$ indicated that their choice of antibiotic considered laboratory results. Inclination to follow the unit policy/protocol was seen among only $43.9 \%$ of responders, and the use of hospital policy/treatment guidelines was only $8.2 \%$ (Table: $1)$. 
Table 1: Factors Determining Antibiotics Prescription among Respondents

\begin{tabular}{|l|l|l|}
\hline Factor & Frequency (N) & Percentage (\%) \\
\hline $\begin{array}{l}\text { Drug Promotional and } \\
\text { Marketing Influences }\end{array}$ & 96 & 97.9 \\
\hline $\begin{array}{l}\text { Clinical Judgment (without } \\
\text { laboratory result) }\end{array}$ & 91 & 93.9 \\
\hline Experience & 86 & 87.8 \\
\hline Cost to Patients & 79 & 80.6 \\
\hline Drug Availability & 79 & 80.6 \\
\hline Epidemiology of Infection & 74 & 75.5 \\
\hline Best Evidence (Literature) & 70 & 71.4 \\
\hline Senior Colleague's Decision & 69 & 70.4 \\
\hline Laboratory Results & 45 & 45.9 \\
\hline Unit Policy & 43 & 43.9 \\
\hline $\begin{array}{l}\text { Hospital Policy (Treatment } \\
\text { Guideline) }\end{array}$ & 8 & 8.2 \\
\hline
\end{tabular}

In terms of the doctor's choices in prescribing, the duration of antibiotic treatment, and the factors determining those choices, $39.8 \%$ of doctors indicated their prescription is individualized considering patient specific conditions. $35.7 \%$ preferred to prescribe for 1 week, $15.3 \%$ indicated they preferred 5 days of treatment and $9.2 \%$ preferred to treat for more than a week. The natures of illness $(56.1 \%)$, and the severity of infections (39.8\%), were the major determinants for choosing the duration of antibiotic treatment. Consideration for the clinical response to treatment was $22.4 \%$, and to the pharmacokinetic and pharmacodynamic properties of the antibiotic was $7.1 \%$ (Table 2a, 2b). 
Table 2 a: Duration of Antibiotics Prescription

\begin{tabular}{|l|l|l|}
\hline Duration & Frequency & $\mathbf{\%}$ \\
\hline Patient Specific & 39 & 39.8 \\
\hline $\mathbf{1}$ week & 35 & 35.7 \\
\hline $\mathbf{5}$ days & 15 & 15.3 \\
\hline$>\mathbf{1}$ week & 9 & 9.2 \\
\hline Total & 98 & 100 \\
\hline
\end{tabular}

Table 2b: Factors Determining Choice of Duration of Antibiotics Prescriptions

\begin{tabular}{|l|l|l|}
\hline Factor & Frequency & \% \\
\hline Nature of infection & 55 & 56.1 \\
\hline Severity of infection & 39 & 39.8 \\
\hline Clinical Response of Patient & 22 & 22.4 \\
\hline Properties of Drug & 7 & 7.1 \\
\hline
\end{tabular}

Nearly three quarters $(72.4 \%)$ of respondents indicated that they prescribe both generic and branded products interchangeably whilst only $5.1 \%$ exclusively prescribed branded products and $22.45 \%$ generic products using the International Non-proprietary Names (INN) (Table: 3 ). $74 \%$ and $82 \%$ of respondents were unaware of the unit and hospital guidelines for antimicrobial therapies respectively.

Table 3: Form of Prescriptions

\begin{tabular}{|l|l|l|}
\hline Form & Frequency & $\%$ \\
\hline $\begin{array}{l}\text { Generic and Branded } \\
\text { (Interchangeably) }\end{array}$ & 71 & 72.4 \\
\hline Generic (Exclusively) & 22 & 22.4 \\
\hline Branded (Exclusively) & 5 & 5.1 \\
\hline
\end{tabular}

\section{Discussion}

The finding that $97 \%$ respondents from most clinical specialties prescribed antibiotics in their daily practice is indicative of the universality of antibiotic use in clinical practice in Nigeria, suggesting the importance of the topic and their rational use. Concerns seen in this initial study include the fact that over $97 \%$ of the doctors alluded to drug promotional and marketing activities influencing their prescribing in some way. This reveals the extent to which drug promotion is prevalent in Nigeria. Even though 
findings from previous studies indicated that the interactions between doctors and the pharmaceutical industries could be mutually beneficial, it is also potentially controversial especially if only biased information is supplied alongside financial rewards $[39,40]$. While some studies argue that physicians believed their prescribing behavior are not easily influenced by the interactions with pharmaceutical representatives as they are able to objectively evaluate such information [41,42], other study demonstrated a significant increase in drug use in subsequent months after promotional activities by pharmaceutical companies [43].Consequently, this is an important factor to consider in planning interventional measures towards promoting rationale antibiotic prescribing. Physician education around rational medicine use has worked well in other countries to reduce the influence of pharmaceutical companies and enhance rational prescribing behavior $[44,45]$. Inappropriate antibiotic prescribing is known to emanate from the trio of behavioural, cultural and contextual factors [28].

Another concern is the high rate of prescribing relying on clinical judgment (94\%) and professional experience (88\%) rather than approved local guidelines based on antibiograms. These findings are indicative of highly prevalent 'decision autonomy' in antibiotic prescribing in hospitals in Nigeria, which urgently needs to be addressed. This could be due to the lack of functioning hospital Drugs and Therapeutic Committee (DTC), approved hospital and unit policies governing antibiotic prescribing practices, instigation of ASPs, inadequate and timely laboratory support and the lack of a reliable supply of antibiotics for uninterrupted duration of treatment. [46-48].

Encouragingly, $76 \%$ of the respondents took the epidemiology of infection into consideration when prescribing antibiotics while $71 \%$ alluded to best evidence influencing their prescribing practices. However, the influence of pharmaceutical companies as well as senior colleague's in determining antibiotics prescription is a concern especially if this leads to inappropriate antibiotic prescribing [30]. The high proportion of antibiotic prescribing influenced by senior colleague's decisions can be explained by the fact that the majority of respondents (over 64\%) in this study were trainees. The finding that $44 \%$ of respondents were aware of the existence of some form of unit based policy on antibiotics could be a reflection of senior colleague's driven practices in their respective clinical units. However, the low percentage of respondents (8\%) who were aware of any hospital based antibiotic policy strongly suggests the lack of existence or implementation of such policies, which urgently needs to be addressed 
along with the establishment of ASPs to improve future antibiotic prescribing. As mentioned, ASPs have been found to be effective to help improve antibiotic prescribing and reduce AMR $[35,49]$. ASPs have helped promote the rational uses of antimicrobials through formulary restrictions, pre-authorization, monitoring, audit and feedback exercises as well as guideline development [50]. Functional ASPs in the hospital should address discrepancies and concerns highlighted in Table 2a and Table $2 \mathrm{~b}$ by standardizing appropriate antibiotics use. This builds on national initiatives ongoing in other African countries such as Ghana and South Africa to improve antibiotic prescribing $[51,52]$.

Most respondents (over 72\%) in this survey prescribed antibiotics in both generic and branded forms interchangeably while $22 \%$ prescribed in generic form exclusively (Table 3). While the survey did not explore the rationale behind these practices in detail, they may be informed by the concerns with the safety and efficacy of generics in Nigeria, as well as issues of affordability as many patients pay from their pockets and the influence of promotional activities $[53,54]$. These issues and associated concerns will be explored in future studies.

\section{Study Limitations}

We are aware that only $58 \%$ of the total number of doctors in the hospital took part. In addition, the proportion of the respondents who were senior doctors was relatively low compared to the total respondents. However, the representation of most clinical specialties and all professional cadres of doctors in this survey suggests that the findings could be indicative of the determinants for antibiotic prescribing practices across the clinical disciplines in this hospital adding robustness to the findings. While the findings in this survey may not necessarily be generalizable to the entire Nigerian clinical population, we believe they constitute useful indications of the likely problems regarding antibiotic prescribing in the country that urgently needs to be addressed.

\section{Conclusion}

The findings in this pilot survey demonstrated a high frequency of antibiotic prescribing among the doctors in this leading tertiary hospital in Nigeria and the indications of inappropriate antibiotic prescribing. There is an urgent need to follow up these findings with a more extensive survey with national coverage to define the problem in greater 
detail and institute evidence based institutional policies and guidelines for promoting rational antimicrobial use across Nigeria. Efforts towards establishment of ASPs and DTCs have commenced in this hospital following analysis of the findings to address highlighted concerns, and will be followed up in future studies.

\section{Conflicts of interest}

No author reports conflicts of interest. The study was self-financed by the authors.

\section{References}

1. World Health Organization. Antimicrobial resistance: global report on surveillance 2014 Available at http://www.who.int/mediacentre/news/release/2014. Accessed on 21/08/2016.

2. Founou RC, Founou LL, Essack SY. Clinical and economic impact of antibiotic resistance in developing countries: A systematic review and meta-analysis. PloS one. 2017;12(12):e0189621

3. Bartlett JG, Gilbert DN, Spellberg B. Seven ways to preserve the miracle of antibiotics. Clinical infectious diseases. 2013;56(10):1445-50

4. Bell BG, Schellevis F, Stobberingh E, Goossens H, Pringle M. A systematic review and meta-analysis of the effects of antibiotic consumption on antibiotic resistance. BMC Infectious Diseases. 2014;14:13

5. de Kraker ME, Davey PG, Grundmann H. Mortality and hospital stay associated with resistant Staphylococcus aureus and Escherichia coli bacteremia: estimating the burden of antibiotic resistance in Europe. PLoS Med. 2011;8(10):e1001104

6. O'Neill J. Securing new drugs for future generations: the pipeline of antibiotics. The review of antimicrobial resistance. Available at URL: https://amrreview.org/sites/default/files/SECURING\%20NEW\%20DRUGS\%20FOR\%20 FUTURE\%20GENERATIONS\%20FINAL\%20WEB_0.pdf

7. Gandra S, Barter DM, Laxminarayan R. Economic burden of antibiotic resistance: how much do we really know? Clinical microbiology and infection. 2014;20(10):973-80

8. Jinks T, Lee N, Sharland M, Rex J, Gertler N, Diver M, et al. A time for action: antimicrobial resistance needs global response. Bull World Health Organ. 2016;94(8):558-a; 
9. Pulcini C, Mainardi JL. Antimicrobial stewardship: an international emergency. Clinical microbiology and infection. 2014;20(10):947-8.

10. Van Boeckel TP, Gandra S, Ashok A, Caudron Q, Grenfell BT, Levin SA, et al. Global antibiotic consumption 2000 to 2010: an analysis of national pharmaceutical sales data. The Lancet Infectious diseases. 2014;14(8):742-50

11. Shallcross LJ, Howard SJ, Fowler T, Davies SC. Tackling the threat of antimicrobial resistance: from policy to sustainable action. Philosophical Transactions of the Royal Society B: Biological Sciences. 2015;370(1670):2014008

12. WHO. Global action plan on antimicrobial resistance. Available at URL: http://www.who.int/antimicrobial-resistance/publications/global-action-plan/en/

13. Goff DA, Mendelson M. Antibiotic stewardship hits a homerun for patients. Lancet ID.2017;17(9):892-893

14. Kimang'a AN. A situational analysis of antimicrobial drug resistance in Africa: are we losing the battle? Ethiop J Health Sci. 2012;22(2):135-43

15. Federal Ministries of Agriculture, Environment and Health of Nigeria. Antimicrobial use and resistance in Nigeria: Situation Analysis and Recommendations (2017). Available at URL: http://www.ncdc.gov.ng/themes/common/docs/protocols/56_1510840387.pdf (Accessed on 11/01/2018).

16. Okesola A O, Aroundegbe T I Antibiotic resistance pattern of uropathogenic Escherichia coli in South West Nigeria. Afr J Med Med Sci 2011; 40: 235-238.

17. Muoneke V, Ibekwe M Ibekwe R Childhood urinary tract infection in abakaliki: etiological organisms and antibiotic sensitivity pattern. Ann Med Health Sci Res 2012; 2: 29-32.

18. Iroezindu M O, Chima E I, Isiguzo G C, Mbata G C, Onyedum C C, Onyedibe K I, Okoli L E Sputum bacteriology and antibiotic sensitivity patterns of community-acquired pneumonia in hospitalized adult patients in Nigeria: a 5year multicentre retrospective study. Scand J Infect Dis 2014; 46: 875-887.

19. Llor C, Bjerrum L. Antimicrobial resistance: risk associated with antibiotic overuse and initiatives to reduce the problem. Therapeutic advances in drug safety. 2014;5(6):229-41 
20. van de Sande-Bruinsma N, Grundmann H, Verloo D, Tiemersma E, Monen J, Goossens H, Ferech M; European Antimicrobial Resistance Surveillance System Group; European Surveillance of Antimicrobial Consumption Project Group. Antimicrobial drug use and resistance in Europe. Emerg Infect Dis 2008; 14: 1722-1730.

21. Davies J, Davies D. Origins and evolution of antibiotic resistance. Microbiol Mol Biol Rev 2010; 74: 417-433.

22. Oduyebo O O, Onwuezobe I A, Olayemi S O, Akintunde A S. Correlating antibiotic consumption with antimicrobial resistance of uropathogens in a university teaching hospital in Lagos, Nigeria. Niger J Clin Pract 2008; 11: 305308.

23. Godman B, Fadare J, Kibuule D, Irawati L, Mubita M, Ogunleye O et al. Initiatives across countries to reduce antibiotic utilization and resistance patterns; impact and implications. Drug Resistance in Bacteria, Fungi, Malaria, and Cancer - Arora, Sajid, \& Kalia Eds Publisher Springer Nature ISBN 978-3319-48682-6 Available at URL:

https://purestrathacuk/portal/en/publications/initiatives-across-countries-toreduce-antibiotic-utilization-and-resistance-patterns(bb445446-fd1d-47b3-8f91def5d9e5e3db)/exporthtml

24. Huttner B, Goossens H, Verheij T, Harbarth S. Characteristics and outcomes of public campaigns aimed at improving the use of antibiotics in outpatients in high-income countries. The Lancet Infectious diseases. 2010;10(1):17-31

25. Nuermberger EL, Bishai WR. Antibiotic resistance in Streptococcus pneumoniae: what does the future hold? Clin Infect Dis. 2004;38(Suppl 4):S363-S71

26. Md Rezal R S, Hassali M A, Alrasheedy A A, Saleem F, Md Yusof F A, Godman B. Physicians' knowledge, perceptions and behaviour towards antibiotic prescribing: a systematic review of the literature. Expert Rev Anti Infect Ther 2015; 13: 665-680.

27. Moro ML, Marchi M, Gagliotti C, Di Mario S, Resi D. Why do paediatricians prescribe antibiotics? Results of an Italian regional project. BMC Pediatr. 2009 Nov 6;9: 69. 
28. Lopez-Vazquez P, Vazquez-Lago JM, Figueiras A. Misprescription of antibiotics in primary care: a critical systematic review of its determinants. J Eval Clin Pract. $2012 ; 18(2): 473-84$.

29. van Buul LW, Sikkens JJ, van Agtmael MA, Kramer MH, van der Steen JT, Hertogh CM. Participatory action research in antimicrobial stewardship: a novel approach to improving antimicrobial prescribing in hospitals and long-term care facilities. J Antimicrob Chemother. 2014; 69(7):1734-41.

30. Charani E, Castro-Sanchez E, Sevdalis N, Kyratsis Y, Drumright L, Shah $\mathrm{N}$, Holmes A. Understanding the determinants of antimicrobial prescribing within hospitals: the role of "prescribing etiquette". Clin Infect Dis. 2013; 57(2):188-96.

31. Calbo E, Alvarez-Rocha L, Gudiol F, Pasquau J. A review of the factors influencing antimicrobial prescribing. Enferm Infecc Microbiol Clin. 2013 Sep;31 Suppl 4:12-5.

32. Nakwatumbah S, Kibuule D, Godman B, Haakuria V, Kalemeera F, Baker A, et al. Compliance to guidelines for the prescribing of antibiotics in acute infections at Namibia's national referral hospital: a pilot study and the implications. Expert review of anti-infective therapy. 2017;15(7):713-21

33. Davey P, Marwick CA, Scott CL, Charani E, McNeil K, Brown E, et al. Interventions to improve antibiotic prescribing practices for hospital inpatients. The Cochrane database of systematic reviews. 2017;2:Cd003543.

34. Nathwani D, Sneddon J, Malcolm W, Wiuff C, Patton A, Hurding S, Eastaway A, Seaton RA, Watson E, Gillies E, Davey P, Bennie M. Scottish Antimicrobial Prescribing Group (SAPG): development and impact of the Scottish National Antimicrobial Stewardship Programme. Int J Antimicrob Agents.2011; 38: 1626.

35. Pulcini C. Antibiotic stewardship: update and perspectives. Clinical microbiology and infection. 2017;23(11):791-2

36. Cox JA, Vlieghe E, Mendelson M, Wertheim H, Ndegwa L, Villegas MV, et al. Antibiotic stewardship in low- and middle-income countries: the same but different? Clinical microbiology and infection. 2017;23(11):812-8

37. World Health Organization. Global Burden of Diseases. 2004. http://www.who.int/healthinfo/global burden disease/GBD report 2004update part4.pdf (Accessed 3 January,2017) 
38. African Population 2017. http://worldpopulationreview.com/continents/africapopulation/ (Accessed 3 January,2017)

39. Collins J. Professionalism and physician interactions with industry. Journal of the American College of Radiology 2006;3(5):325-32.

40. Fleischman W, Agrawal S, King M, Venkatesh AK, Krumholz HM, McKee D, et al. Association between payments from manufacturers of pharmaceuticals to physicians and regional prescribing: cross sectional ecological study. BMJ. 2016;354:i4189

41. Zipkin DA, Steinman MA. Interactions between pharmaceutical representatives and doctors in training. A thematic review. Journal of general internal medicine. 2005;20(8):777-86.

42. Fischer MA, Keough ME, Baril JL, Saccoccio L, Mazor KM, Ladd E, et al. Prescribers and pharmaceutical representatives: why are we still meeting? Journal of general internal medicine. 2009;24(7):795-801.

43. Orlowski JP, Wateska L. The effects of pharmaceutical firm enticements on physician prescribing patterns. There's no such thing as a free lunch. Chest. 1992;102(1):270-3.

44. Gustafsson LL, Wettermark B, Godman B, Andersen-Karlsson E, Bergman U, Hasselstrom J, et al. The 'wise list'- a comprehensive concept to select, communicate and achieve adherence to recommendations of essential drugs in ambulatory care in Stockholm. Basic \& clinical pharmacology \& toxicology. 2011;108(4):224-33

45. Bjorkhem-Bergman L, Andersen-Karlsson E, Laing R, Diogene E, Melien O, Jirlow M, et al. Interface management of pharmacotherapy. Joint hospital and primary care drug recommendations. European journal of clinical pharmacology. 2013;69 Suppl 1:73-8

46. Nakwatumbah S, Kibuule D, Godman B, Haakuria V, Kalemeera F, Baker A, et al. Compliance to guidelines for the prescribing of antibiotics in acute infections at Namibia's national referral hospital: a pilot study and the implications. Expert review of anti-infective therapy. 2017;15(7):713-21

47. Fadare J, Ogunleye O, Enato E, Godman B, Gustafsson LL. Presence and Functionality of Drug and Therapeutics Committees (DTC) in Selected Nigerian Hospitals - Results of a Pilot Study. MURIA Conference PV NCD DU Studies. 2016: 2 (Available at URL: http://muria.nmmu.ac.za/2nd-MURIA-TrainingWorkshop-and-Symposium,-25-27-J) 
48. Fadare J, Olayinka Ogunleye, Arno Muller, Garba Iliyasu, Okezie Enwere, B Godman. The current state of antimicrobial stewardship programs in Nigerian tertiary healthcare facilities. MURIA 3 2017; 9. Available at URL:

http://muria.mandela.ac.za/muria/media/Store/documents/Abstract $\% 20$ book $\% 20$ -\%20MURAI\%203/MURIA3-AbstractBook-July-2017.pdf

49. Davey P, Marwick CA, Scott CL, et al. Interventions to improve antibiotic prescribing practices for hospital inpatients. The Cochrane database of systematic reviews. Feb 09 2017;2:Cd003543.

50. Nasr Z, Paravattil B, Wilby KJ. The impact of antimicrobial stewardship strategies on antibiotic appropriateness and prescribing behaviours in selected countries in the Middle East: a systematic review. Eastern Mediterranean health journal. Aug 20 2017;23(6):430-440.

51. Meyer JC, Schellack N, Stokes J, Lancaster R, Zeeman H, Defty D, et al. Ongoing Initiatives to Improve the Quality and Efficiency of Medicine Use within the Public Healthcare System in South Africa; A Preliminary Study. Frontiers in pharmacology. 2017;8:751

52. Afriyie DK, Amponsah SK, Dogbey J, Agyekum K, Kesse S, Truter I, et al. A pilot study evaluating the prescribing of ceftriaxone in hospitals in Ghana: findings and implications. Hospital practice. 2017;45(4):143-9

53. Fadare JO, Adeoti AO, Desalu OO, Enwere OO, Makusidi AM, Ogunleye O, et al. The prescribing of generic medicines in Nigeria: knowledge, perceptions and attitudes of physicians. Expert review of pharmacoeconomics \& outcomes research. 2016;16(5):639-50.

54. Ezenduka C,UbochV, Ogbonna BO. The Utilization Pattern and Costs Analysis of Psychotropic Drugs at a Neuropsychiatric Hospital in Nigeria. British Journal of Pharmaceutical Research. 2014;4(3):325-37 